\title{
Microwave Assisted Hydrolysis of Holocellulose Catalyzed with Sulfonated Char Derived from Lignin-Rich Residue
}

\author{
Kui Wang, ${ }^{1,2,3}$ Xinfeng Xie, ${ }^{3}$ Zhan Si, ${ }^{1}$ Jianchun Jiang, ${ }^{1,2}$ and Jingxin Wang ${ }^{3}$ \\ ${ }^{1}$ Institute of Chemical Industry of Forest Products, CAF, Nanjing 210042, China \\ ${ }^{2}$ Research Institute for Forestry New Technology, CAF, Beijing 100091, China \\ ${ }^{3}$ Division of Forestry and Natural Resources, West Virginia University, Morgantown, WV 26505, USA \\ Correspondence should be addressed to Jianchun Jiang; bio-energy@163.com and Jingxin Wang; jxwang@wvu.edu
}

Received 26 September 2014; Revised 2 December 2014; Accepted 3 December 2014

Academic Editor: Jie Dai

Copyright (C) 2015 Kui Wang et al. This is an open access article distributed under the Creative Commons Attribution License, which permits unrestricted use, distribution, and reproduction in any medium, provided the original work is properly cited.

\begin{abstract}
A microwave assisted green process has been developed for production of sugars through liquefying holocellulose catalyzed with sulfonated char derived from the lignin-rich residue produced during pretreatment of lignocellulose. Various reaction parameters including the hydrolysis temperature, hydrolysis time, catalyst content, and the ratio of water to feedstock were evaluated. The maximum sugars yield of $82.6 \%$ (based on the dry mass of holocellulose) was obtained under the optimum reaction conditions. The sulfonated char showed superior catalytic performance to that of dilute sulfuric acid in converting holocellulose into sugars under microwave irradiation.
\end{abstract}

\section{Introduction}

Hydrolysis of holocellulose (cellulose and hemicellulose) is a key technology to obtain the sugars which are pivotal platform compounds for a range of industrially important chemicals, such as ethanol, butanol, and hydrocarbon [13]. Substantial effort has been made to develop appropriate hydrolysis processes using liquid acids [4-6], enzymes [7, $8]$, supercritical water $[9,10]$, and solid catalysts [11-18] for hydrolysis of cellulose. Although liquid acid hydrolysis has received considerable attention and has been implemented on relatively large scales, the process is energy-inefficient, requiring separation, recycling, and treatment of the waste sulfuric acid. Enzymatic hydrolysis has been proven to be one of the most promising green hydrolysis technologies and operated in commercial applications. However, the high cost of enzymatic hydrolysis cannot be ignored. Supercritical water treatment for holocellulose hydrolysis has also received attention in recent years. The process, however, is carried out at extremely high temperatures and short residence time, causing partial degradation of the produced sugars $[9,10]$.

The move toward more environmentally benign processes has stimulated the development of solid acid catalysts, which are nontoxic and easy in separation and have a high strength of acidity. Solid acid catalysts, including inorganic oxides [11], zeolites [12], cation-exchanged resins [13], polymers [14], and heteropolyacids [15], have been studied on the hydrolysis of cellulose. However, these heterogeneously catalytic processes show poor hydrolysis efficiency due to a mass transfer resistance between solid acids and the insoluble cellulose in water. Recently, Suganuma et al. [16], Wu et al. [17], and Gupta and Lee [18] have developed a carbonaceous solid acid bearing $\mathrm{SO}_{3} \mathrm{H}, \mathrm{COOH}$, and phenolic hydroxyl $(\mathrm{OH})$ groups in the framework of the amorphous carbon. This carbonaceous solid acid was proved to be an excellent candidate for the catalytic hydrolysis of cellulose. The amorphous carbon is a solid Bronsted acid catalyst consisting of flexible polycyclic carbon sheets with $\mathrm{SO}_{3} \mathrm{H}, \mathrm{COOH}$, and phenolic hydroxyl $(\mathrm{OH})$ groups in a three-dimensional network that can be readily prepared by partial carbonization of natural organic compounds, such as sugar, cellulose, and starch, followed by sulfonation of the resulting amorphous carbon [19].

In this study, we developed an environmentally benign hydrolysis approach for the saccharification of holocellulose. As shown in Figure 1, the green and effective hydrolysis process was catalyzed by a sulfonated char derived from 


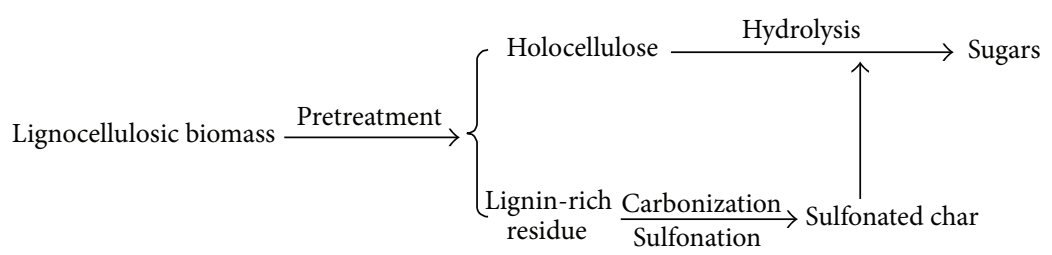

FIGURE 1: Schematic route of the holocellulose hydrolysis catalyzed by sulfonated char derived from lignin-rich pretreatment residues.

lignin-rich pretreatment residues with a small amount of water under microwave irradiation. After reaction, the catalyst can be easily separated from the products by filtration and effectively reused for further hydrolysis. This hydrolysis approach may also be employed as the guidance for efficient pretreatment and comprehensive utilization of lignocellulosic biomass.

\section{Experimental}

2.1. Materials. The hybrid poplar was collected from West Virginia University Experimental Forest. The holocellulose was separated from raw poplar particles and the composition of holocellulose was analyzed (mass percent: cellulose $63.2 \%$, xylan $32.7 \%$, and others $4.1 \%$ ). Sulfuric acid and other chemicals (if applicable) were purchased from Sigma-Aldrich, Inc.

2.2. Preparation of Sulfonated Char. According to the typical procedure [18], the carbonaceous catalyst with $\mathrm{SO}_{3} \mathrm{H}$ groups was prepared from the poplar (Populus cathayana) pretreatment residues (mass percent: lignin $65 \%$, cellulose $25 \%$, and others $10 \%)$. In a typical preparation procedure $[19,20], 30 \mathrm{~g}$ of the poplar pretreatment residue was heated for $5 \mathrm{~h}$ at $723 \mathrm{~K}$ under $\mathrm{N}_{2}$ flow to produce a black solid, which was then ground into powder using universal high-speed smashing machine (QE-500, Zhejing Yili Industry and Trade Co. Ltd.). $10 \mathrm{~g}$ of the powder was then boiled in fuming sulfuric acid $\left(15 \mathrm{wt} \% \mathrm{SO}_{3}\right)$ at $353 \mathrm{~K}$ under $\mathrm{N}_{2}$ for $8 \mathrm{~h}$. After cooling to room temperature, the suspension was filtered using cellulose filter paper (pore size of 30-50 $\mu \mathrm{m}$ ) to yield a black precipitate that was washed repeatedly with hot distilled water $(>353 \mathrm{~K})$ until no sulfate ions could be detected. The washed precipitate was dried at $383 \mathrm{k}$ for $12 \mathrm{~h}$ to obtain a sulfonated char bearing $\mathrm{SO}_{3} \mathrm{H}, \mathrm{OH}$, and $\mathrm{COOH}$ groups.

2.3. Characterization of Sulfonated Char. The specific surface area of the sulfonated char was obtained by Brunauer Emmett Teller surface analyzer (BET, ASAP2020M, Micromeritics). Scanning electron microscopy (SEM) analysis was conducted on a Hitachi 3400-1 electronic microscope working at $30 \mathrm{kv}$. FTIR spectrum was recorded on a Fourier transform infrared spectroscopy (FTIR, I80, Nicolet) using the standard $\mathrm{KBr}$ disc method. The samples were scanned between 400 and $4000 \mathrm{~cm}^{-1}$ with a resolution of $0.4 \mathrm{~cm}^{-1}$. $\mathrm{X}$-ray diffraction (XRD) patterns were collected on a Bruker D8 Focus Advance diffractometer using $\mathrm{Cu} \mathrm{K} \alpha$ radiation (wavelength $\lambda=1.5406 \AA$ ). According to the FT-IR analysis result, the sulfonated char possesses three functional groups: $\mathrm{SO}_{3} \mathrm{H}, \mathrm{COOH}$, and phenolic $\mathrm{OH}$. The amount of groups was estimated by elemental analysis (EA, Thermo Scientific Flash $2000 \mathrm{CHNS} / \mathrm{O}$ ) and cation-exchange analysis [16]. The densities of $\mathrm{SO}_{3} \mathrm{H}$ groups were estimated based on the sulfur content determined from sample compositions obtained by elemental analysis. The total $\mathrm{SO}_{3} \mathrm{H}+\mathrm{COOH}$ and $\mathrm{SO}_{3} \mathrm{H}+$ $\mathrm{COOH}+\mathrm{OH}$ contents were estimated from the exchange of $\mathrm{Na}^{+}$in aqueous $\mathrm{NaCl}$ and $\mathrm{NaOH}$ solutions, respectively.

2.4. Hydrolysis of Holocellulose and Analysis of the Produced Sugars. The holocellulose was separated from raw poplar (Populus cathayana) particles [18]. In a typical experimental run, $0.2 \mathrm{~g}$ oven-dried holocellulose powder and $0.2 \mathrm{~g}$ carbonaceous catalyst were mixed and milled for 10 minutes in an agate mortar and then placed into a Pyrex tube. Distilled water $(3 \mathrm{~mL})$ was then added to the powdered mixture before the Pyrex tube was sealed and placed in a microwave reactor (CEM, Discovers). The mixture was stirred by a magnetic stirrer during the reaction. After the desired reaction time, the reaction mixture was neutralized with $0.4 \mathrm{~mol} / \mathrm{L}$ of $\mathrm{NaOH}$ solution $(10 \mathrm{~mL})$ and filtered with filter paper (pore size of $30-$ $50 \mu \mathrm{m})$.

The aqueous filtrate was analyzed using the Dionex Capillary Ion Chromatography System (ICS5000 Thermo Fisher) with a pulsed amperometric detector and a CarboPac PA-10 (4 mm) column. $\mathrm{NaOH}(18 \mathrm{mM})$ aqueous solution was used as elution solvent at a flow rate of $1.0 \mathrm{~mL} \mathrm{~min}^{-1}$. The yield of total sugars (based on the dry mass of holocellulose) was calculated using the following equation: Total sugars yield $(\%)=$ [amount $(\mathrm{g})$ of oligose + amount $(\mathrm{g})$ of monose]/amount (g) of holocellulose.

The catalytic performance of the sulfonated char was examined by the microwave assisted hydrolysis of holocellulose under various conditions. The experimental parameters were evaluated as follows: hydrolysis temperature from $373 \mathrm{~K}$ to $403 \mathrm{~K}$, reaction time from $20 \mathrm{~min}$ to $100 \mathrm{~min}$, catalyst/substrate (holocellulose) ratio from 0.25 to 1.5 , and liquid/solid (catalyst + holocellulose) ratio from 2.5 to 12.5 . The reusability of the sulfonated char was also studied and the respective catalytic performance was compared with that of dilute sulfuric acid.

\section{Results and Discussion}

3.1. Properties of the Sulfonated Char. The BET analysis showed that the specific surface area of sulfonated char was $2 \mathrm{~m}^{2} \mathrm{~g}^{-1}$, which is in the range of a typical lignin carbon processed at similar temperatures [21]. The SEM analysis (Figure 2(a)) showed that the sulfonated char particles exhibited an irregular morphology with the particle size 


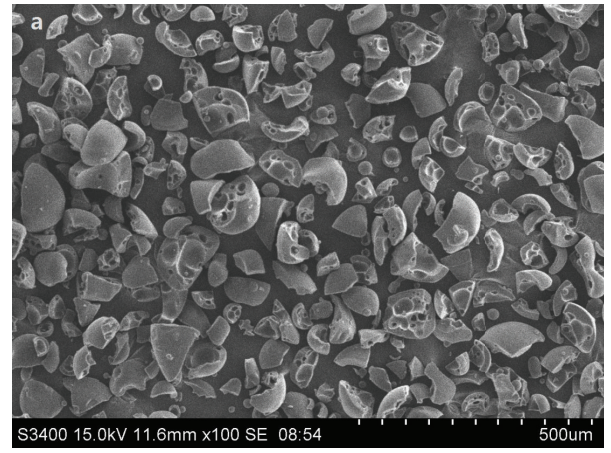

(a)

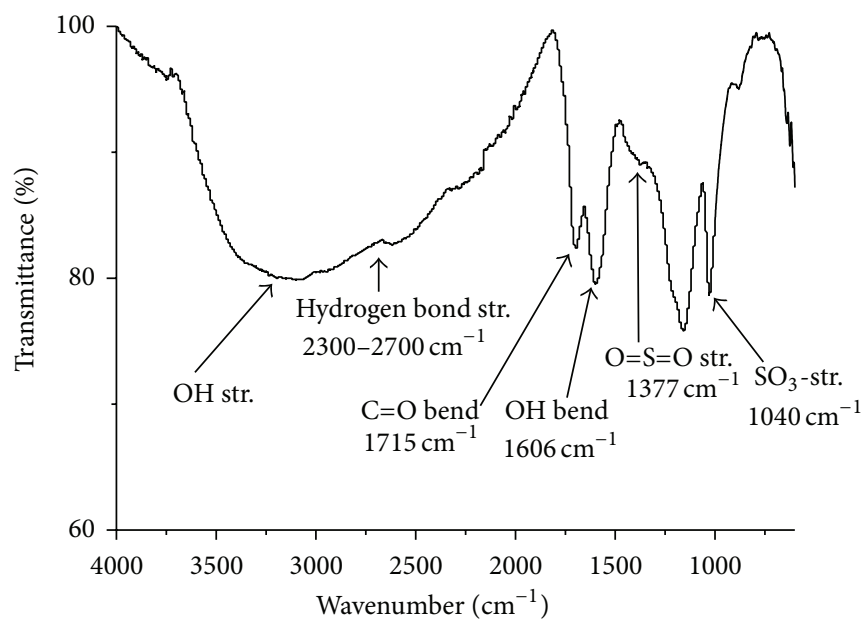

(b)

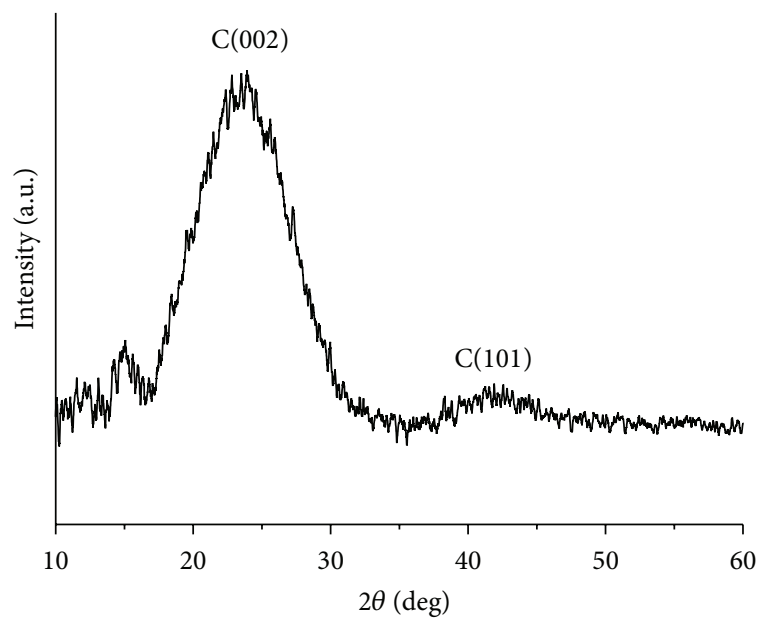

(c)

FIGURE 2: The SEM image (a), FTIR spectrum (b), and XRD pattern (c) for the prepared sulfonated char.

ranging from 30 to $100 \mu \mathrm{m}$. The FTIR spectrum (Figure 2(b)) showed two vibration bands at $1040 \mathrm{~cm}^{-1}\left(\mathrm{SO}_{3}\right.$-stretching) and $1377 \mathrm{~cm}^{-1}\left(\mathrm{O}=\mathrm{S}=\mathrm{O}\right.$ stretching in $\left.\mathrm{SO}_{3} \mathrm{H}\right)$ which verified the existence of $\mathrm{SO}_{3} \mathrm{H}$ groups. The vibration bands at $1606 \mathrm{~cm}^{-1}(-\mathrm{OH})$ and $1715 \mathrm{~cm}^{-1}(\mathrm{C}=\mathrm{O})$ can be assigned to the $-\mathrm{COOH}$ groups in the sulfonated char. The broadband at $2300-2700 \mathrm{~cm}^{-1}$ suggested an overtone (Fermi resonance) of the bending mode of strong hydrogen bond [16]. The XRD pattern (Figure 2(c)) of the sulfonated char exhibited two broad diffraction peaks at $22.5^{\circ}$ and $42.0^{\circ}$ of $2 \theta$, which is typical for amorphous carbon composed of aromatic carbon sheets oriented in a considerably random pattern [22]. Elemental analysis results (C 53.745; H 3.389; O 37.868; S 4.998) and cation-exchange experiment revealed that the samples composition is $\mathrm{CH}_{0.757} \mathrm{O}_{0.528} \mathrm{~S}_{0.034}$ and that the amounts of $\mathrm{SO}_{3} \mathrm{H}, \mathrm{COOH}$, and phenolic $\mathrm{OH}$ groups bonded to the char are $1.53,0.30$, and $1.69 \mathrm{mmol} \mathrm{g}^{-1}$, respectively.

3.2. Hydrolysis of Holocellulose under Microwave Irradiation. As shown in Figure 3, the sugar yield of holocellulose increased with increasing reaction temperature in the first

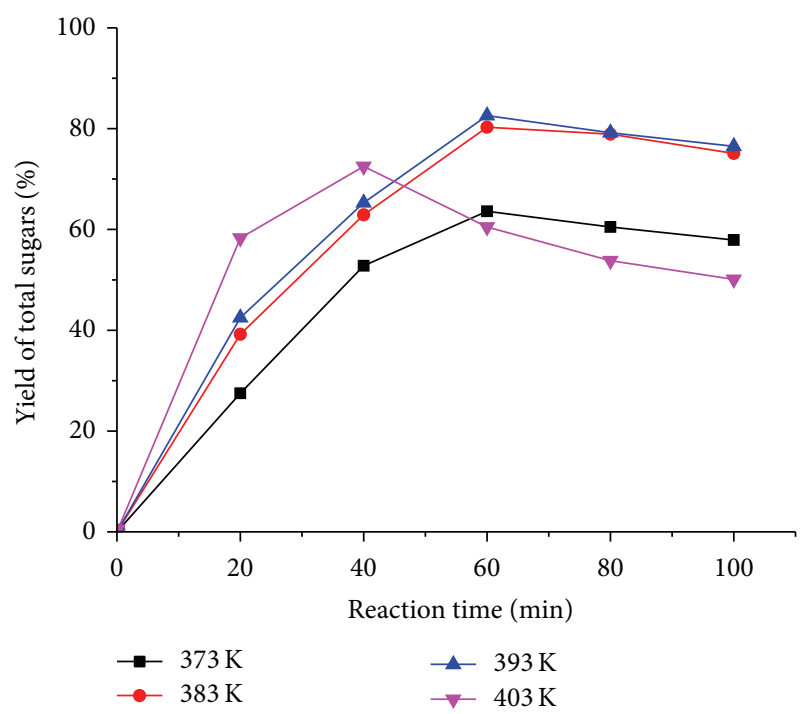

FIGURE 3: Effect of reaction temperature on the sulfonated char catalyzed hydrolysis of holocellulose. Reaction conditions: $0.2 \mathrm{~g}$ holocellulose, $0.2 \mathrm{~g}$ catalyst, $3 \mathrm{~mL} \mathrm{H}_{2} \mathrm{O}$, and microwave irradiation $(300 \mathrm{~W})$ for $60 \mathrm{~min}$. 


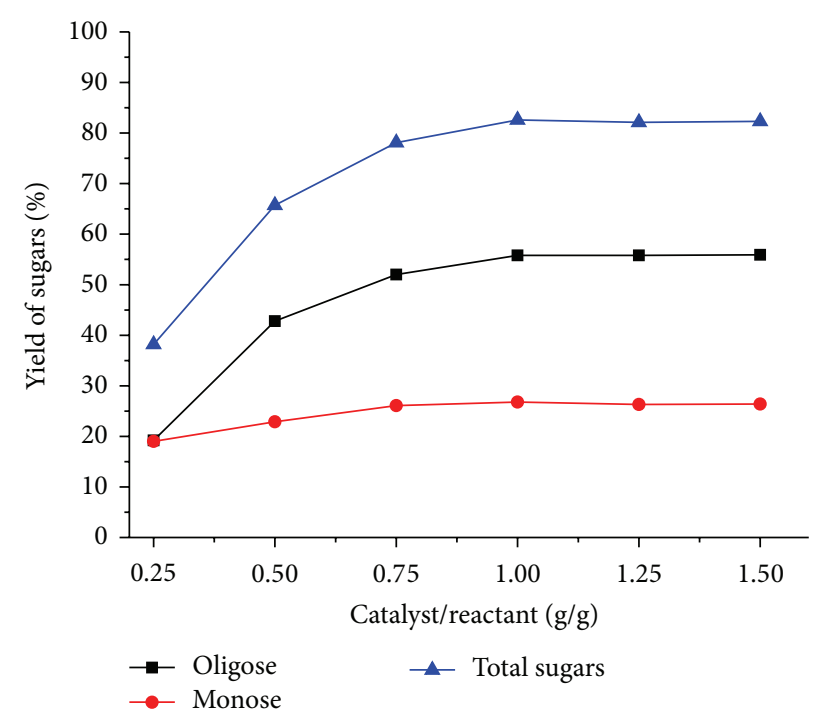

(a)

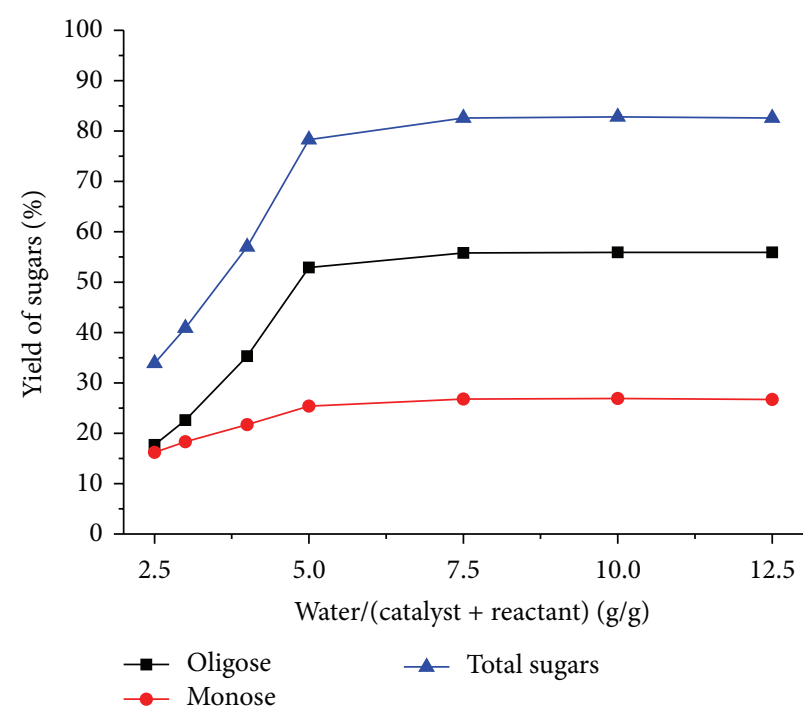

(b)

FIGURE 4: (a) Effect of catalyst/substrate ratio on the sulfonated char catalyzed hydrolysis of holocellulose. Reaction conditions: $0.2 \mathrm{~g}$ holocellulose, $3 \mathrm{~mL} \mathrm{H}_{2} \mathrm{O}, 393 \mathrm{~K}$, and microwave irradiation $(300 \mathrm{~W})$ for $60 \mathrm{~min}$. (b) Effect of liquid/solid ratio on the sulfonated char catalyzed hydrolysis of holocellulose. Reaction conditions: $0.2 \mathrm{~g}$ holocellulose, $0.2 \mathrm{~g}$ catalyst, $393 \mathrm{~K}$, and microwave irradiation ( $300 \mathrm{~W}$ ) for $60 \mathrm{~min}$.

40 minutes of the reaction. However, it started to decrease with longer reaction time, indicating thermal degradation of monose at elevated temperature. The highest sugar yield of $82.6 \%$ was obtained when the holocellulose was treated at $393 \mathrm{~K}$ for 60 minutes. This optimum reaction temperature and reaction time were used in our studies on other reaction parameters. The results indicated that saccharification of the polysaccharides and thermal degradation of the produced monose and oligose were taking place synchronously in the reaction system.

The effects of catalyst/substrate (holocellulose) ratio and liquid/solid (catalyst + holocellulose) ratio were evaluated using the optimal reaction temperature and time. As shown in Figure 4(a), the yield of monose and oligose increased with increasing catalyst/substrate ratio up to 1.00. Increasing the liquid/solid ratio significantly increased the sugar yield when the ratio was lower than 5.0 as shown in Figure 4(b). No further increase in the sugar yield was apparent for liquid/solid ratios above 7.5 .

To evaluate reusability, sulfonated char samples (reused up to three times) were investigated by reacting a mixture of $0.2 \mathrm{~g}$ catalyst, $0.2 \mathrm{~g}$ holocellulose, and $3 \mathrm{~mL}$ water under $300 \mathrm{~W}$ microwave irradiation for $60 \mathrm{~min}$. The unreacted sulfonated char and those recovered once, twice, and 3 times were designated SC0, SC1, SC2, and SC3, respectively. Additionally, the catalytic performance of the sulfonated char was compared with that of dilute sulfuric acid. After the first run at $393 \mathrm{~K}$ for $60 \mathrm{~min}$, the sulfonated char was recovered from the hydrolytic solution by filtration followed by washing with distilled water. The recovered catalyst was reused by directly mixing with fresh holocellulose and water. As shown in Table 1, the catalytic performance of the sulfonated char decreased with the recovery times, indicating reduced active sites on the surface of the sulfonated char. It is possible that
TABLE 1: Comparison of the catalytic performance of reused sulfonated char and dilute sulfuric acid.

\begin{tabular}{lcccccc}
\hline Yield/\% & $\mathrm{SC}^{\mathrm{a}}$ & $\mathrm{SCl}^{\mathrm{a}}$ & $\mathrm{SC}^{\mathrm{a}}$ & $\mathrm{SC}^{\mathrm{a}}$ & $\mathrm{H}_{2} \mathrm{SO}_{4}{ }^{\mathrm{a}}$ & $\mathrm{H}_{2} \mathrm{SO}_{4}{ }^{\mathrm{b}}$ \\
\hline Monose & 26.8 & 23.9 & 20.4 & 16.1 & 12.2 & 4.9 \\
Oligose & 55.8 & 54.6 & 52.5 & 49.1 & 10.3 & 27.2 \\
Sugars & 82.6 & 78.5 & 72.9 & 65.2 & 22.5 & 31.7 \\
\hline
\end{tabular}

${ }^{a}$ Reaction at $393 \mathrm{~K} ;{ }^{\text {b }}$ reaction at $423 \mathrm{~K}$.

some active acid sites were blocked by the unreacted holocellulose residues left in aqueous solution $[18,23]$. However, even after being recovered three times, the sulfonated char still has much higher catalytic ability than dilute sulfuric acid in hydrolysis of holocellulose. The poor performance of dilute sulfuric acid in hydrolysis of holocellulose was attributed to the low catalytic activity at $393 \mathrm{~K}$ and the degradation of produced sugars when high temperature ( $423 \mathrm{~K}$ or more) was employed.

\section{Conclusions}

An environmentally friendly hydrolysis process alternative to dilute sulfuric acid was developed to efficiently convert holocellulose into useful sugars under microwave irradiation. The catalyst, a sulfonated char, was produced from lignin-rich residues from pretreatment of lignocellulosic biomass. The catalyst showed excellent catalytic performance in hydrolysis of holocellulose and low toxicity for microbial activity, which is different from sulfuric acid. This approach may also be exploited for the direct hydrolysis of lignocellulosic biomass into sugars and other useful chemicals. 


\section{Conflict of Interests}

The authors declare that there is no conflict of interests regarding the publication of this paper.

\section{Acknowledgment}

This work was supported by National Nonprofit Institute Research Grant of CAFINT2013C05.

\section{References}

[1] A. J. Ragauskas, C. K. Williams, B. H. Davison et al., "The path forward for biofuels and biomaterials," Science, vol. 311, no. 5760, pp. 484-489, 2006.

[2] J. N. Chheda, G. W. Huber, and J. A. Dumesic, "Liquid-phase catalytic processing of biomass-derived oxygenated hydrocarbons to fuels and chemicals," Angewandte Chemie-International Edition, vol. 46, no. 38, pp. 7164-7183, 2007.

[3] Y.-B. Huang and Y. Fu, "Hydrolysis of cellulose to glucose by solid acid catalysts," Green Chemistry, vol. 15, no. 5, pp. 10951111, 2013.

[4] G. Sanchez, L. Pilcher, C. Roslander, T. Modig, M. Galbe, and G. Liden, "Dilute-acid hydrolysis for fermentation of the Bolivian straw material Paja Brava," Bioresource Technology, vol. 93, no. 3, pp. 249-256, 2004.

[5] P. Lenihan, A. Orozco, E. O'Neill, M. N. M. Ahmad, D. W. Rooney, and G. M. Walker, "Dilute acid hydrolysis of lignocellulosic biomass," Chemical Engineering Journal, vol. 156, no. 2, pp. 395-403, 2010.

[6] A. S. Amarasekara and B. Wiredu, "Aryl sulfonic acid catalyzed hydrolysis of cellulose in water," Applied Catalysis A: General, vol. 417-418, pp. 259-262, 2012.

[7] B. Yang, Z. Y. Dai, S. Y. Ding, and C. E. Wyman, "Enzymatic hydrolysis of cellulosic biomass," Biofuels, vol. 2, no. 4, pp. 421450, 2011.

[8] D. Kumar and G. S. Murthy, "Stochastic molecular model of enzymatic hydrolysis of cellulose for ethanol production," Biotechnology for Biofuels, vol. 6, no. 1, article no. 63, 2013.

[9] M. Sasaki, Z. Fang, Y. Fukushima, T. Adschiri, and K. Arai, "Dissolution and hydrolysis of cellulose in subcritical and supercritical water," Industrial and Engineering Chemistry Research, vol. 39, no. 8, pp. 2883-2890, 2000.

[10] K. Ehara and S. Saka, "A comparative study on chemical conversion of cellulose between the batch-type and flow-type systems in supercritical water," Cellulose, vol. 9, no. 3-4, pp. 301311, 2002.

[11] T. Zhang, N. Ji, M. Y. Zheng, and J. G. Chen, "Uses of aluminum oxides supported noble metal catalyst in cellulose hydrogenation hydrolyzation," CN Patent 101428214, 2007.

[12] Z. H. Zhang and Z. B. Zhao, "Solid acid and microwave-assisted hydrolysis of cellulose in ionic liquid," Carbohydrate Research, vol. 344, no. 15, pp. 2069-2072, 2069.

[13] R. Rinaldi, R. Palkovits, and F. Schuth, "Depolymerization of cellulose using solid catalysts in ionic liquids," Angewandte Chemie International Edition, vol. 47, no. 42, pp. 8047-8050, 2008.

[14] G. Akiyama, R. Matsuda, H. Sato, M. Takata, and S. Kitagawa, "Cellulose hydrolysis by a new porous coordination polymer decorated with sulfonic acid functional groups," Advanced Materials, vol. 23, no. 29, pp. 3294-3297, 2011.
[15] K.-I. Shimizu, H. Furukawa, N. Kobayashi, Y. Itaya, and A. Satsuma, "Effects of Brønsted and Lewis acidities on activity and selectivity of heteropolyacid-based catalysts for hydrolysis of cellobiose and cellulose," Green Chemistry, vol. 11, no. 10, pp. 1627-1632, 2009.

[16] S. Suganuma, K. Nakajima, M. Kitano et al., "Hydrolysis of cellulose by amorphous carbon bearing $\mathrm{SO} 3 \mathrm{H}, \mathrm{COOH}$, and $\mathrm{OH}$ groups," Journal of the American Chemical Society, vol. 130, no. 38, pp. 12787-12793, 2008.

[17] Y. Y. Wu, Z. H. Fu, Q. Xu, F. Liu, C. L. Lu, and L. Q. Mao, "Microwave-assisted hydrolysis of crystalline cellulose catalyzed by biomass char sulfonic acids," Green Chemistry, vol. 12, no. 4, pp. 696-700, 2010.

[18] R. Gupta and Y. Y. Lee, "Pretreatment of hybrid poplar by aqueous ammonia," Biotechnology Progress, vol. 25, no. 2, pp. 357-364, 2009.

[19] Y. Jiang, X. Li, X. Wang et al., "Effective saccharification of lignocellulosic biomass over hydrolysis residue derived solid acid under microwave irradiation," Green Chemistry, vol. 14, no. 8, pp. 2162-2167, 2012.

[20] E. T. Lu and S. G. Love, "Gravitational tractor for towing asteroids," Nature, vol. 438, no. 7065, pp. 177-178, 2005.

[21] X. Xie, B. Goodell, D. Zhang et al., "Characterization of carbons derived from cellulose and lignin and their oxidative behavior," Bioresource Technology, vol. 100, no. 5, pp. 1797-1802, 2009.

[22] N. Tsubouchi, C. Xu, and Y. Ohtsuka, "Carbon crystallization during high-temperature pyrolysis of coals and the enhancement by calcium," Energy and Fuels, vol. 17, no. 5, pp. 1119-1125, 2003.

[23] X. Tian, F. Su, and X. S. Zhao, "Sulfonated polypyrrole nanospheres as a solid acid catalyst," Green Chemistry, vol. 10, no. 9, pp. 951-956, 2008. 

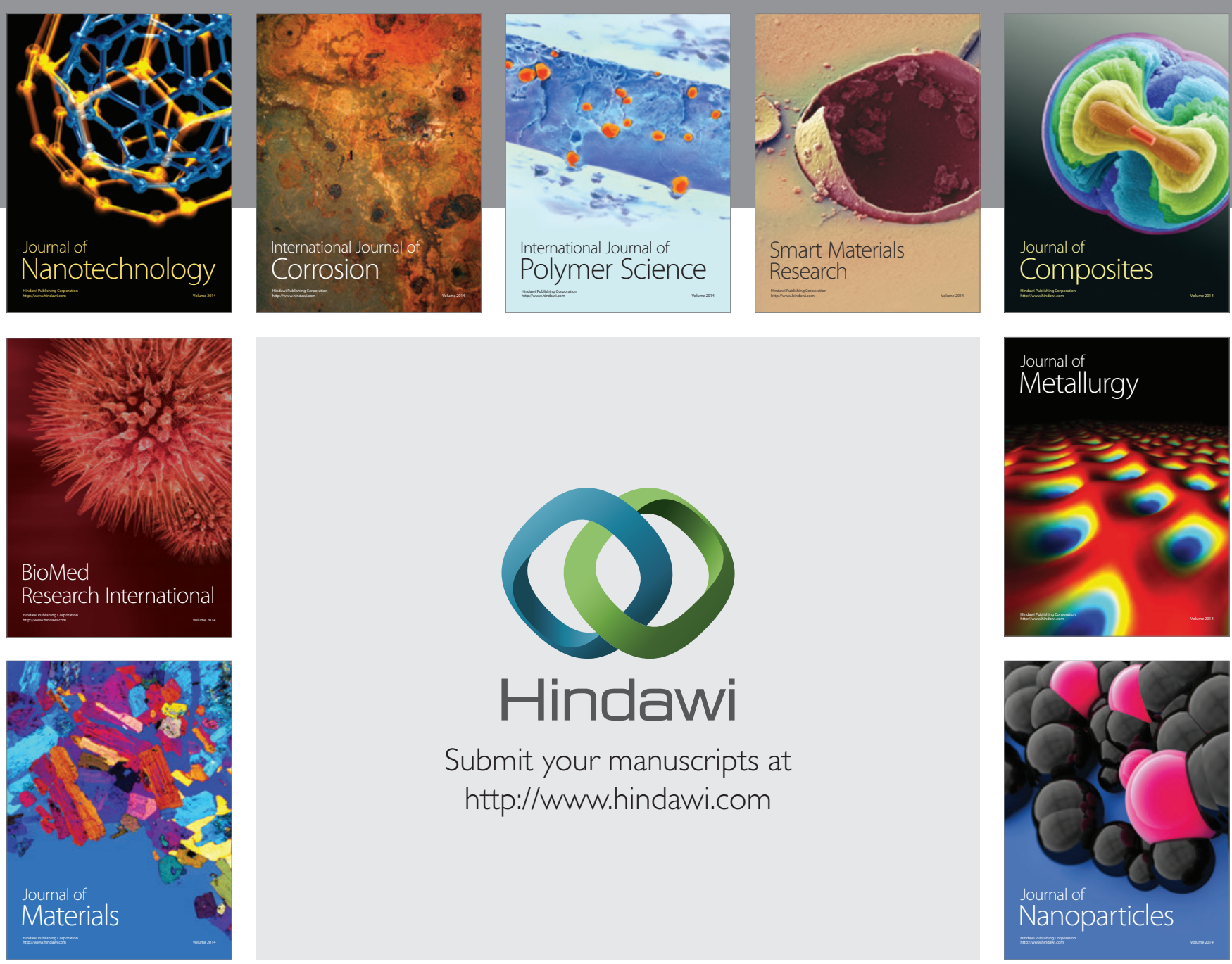

Submit your manuscripts at http://www.hindawi.com
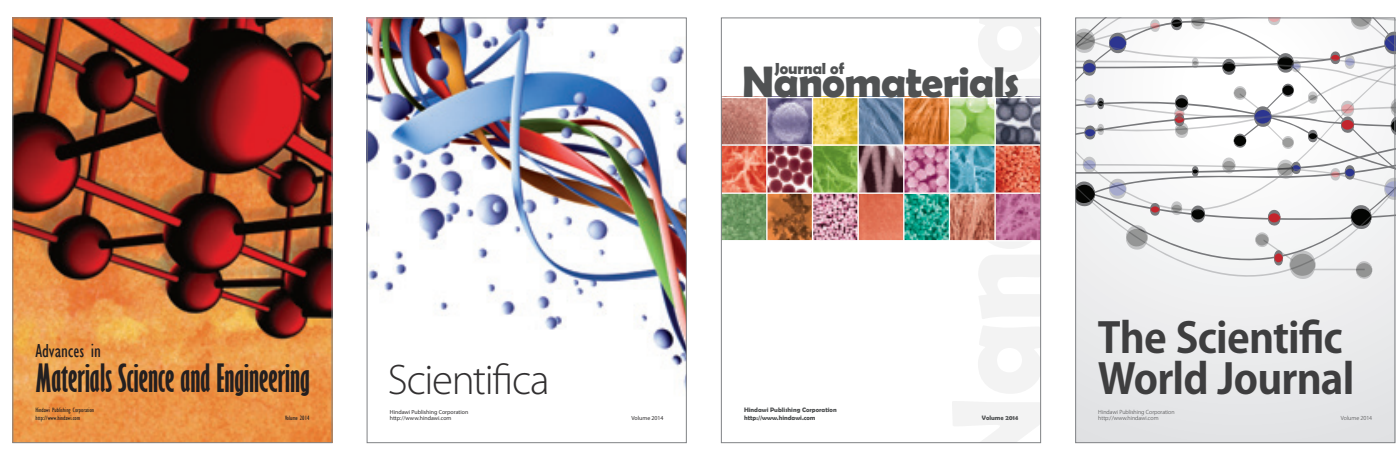

\section{The Scientific World Journal}
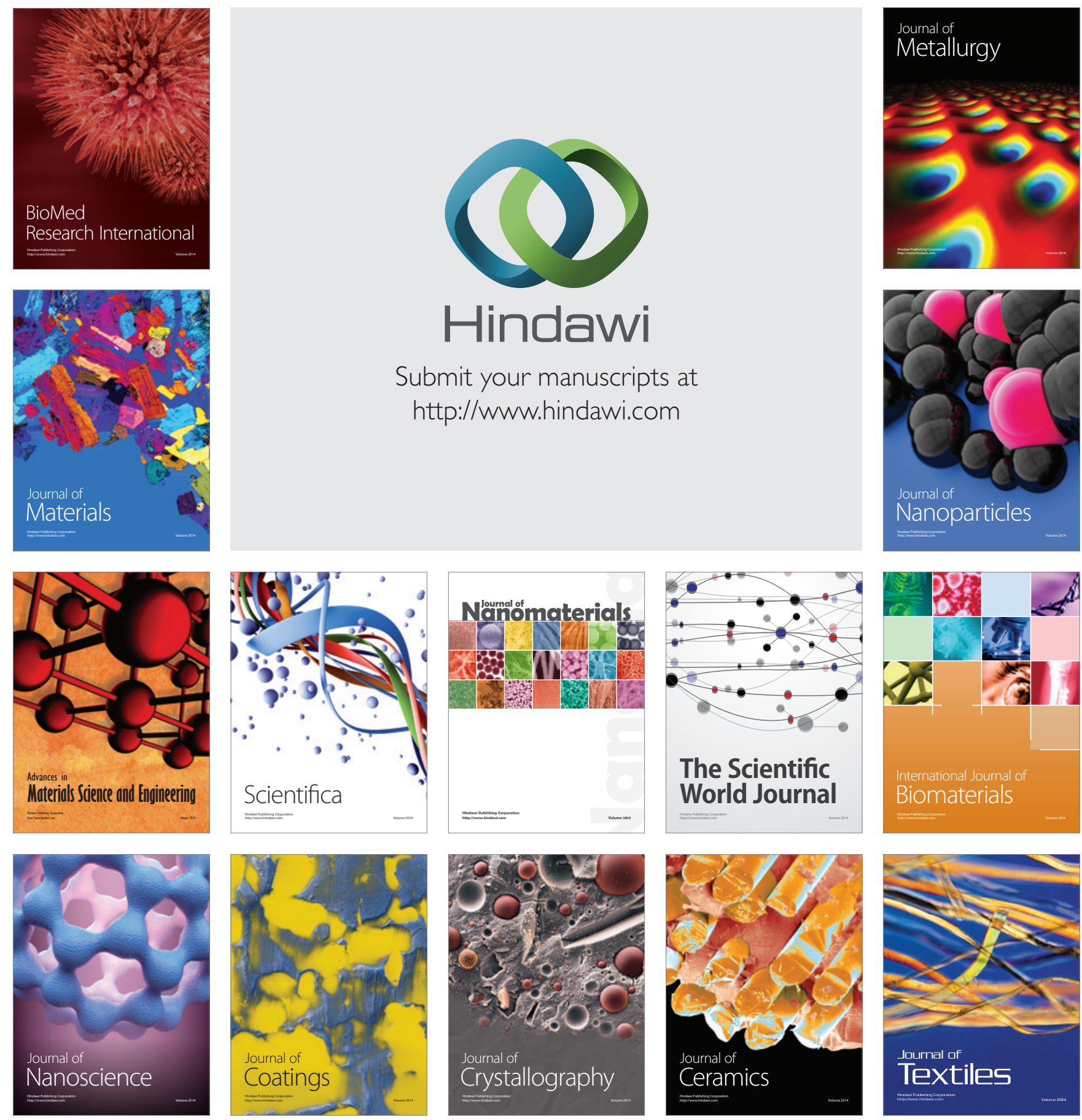